\title{
The use of unmanned aircraft system technology for highwall mapping at Isibonelo Colliery, South Africa
}

\author{
by M. Katuruza' ${ }^{1}$ and C. Birch ${ }^{2}$
}

\section{Synopsis}

The purpose of this study was to demonstrate unmanned aircraft system (UAS) technology in opencast highwall mapping using the experience at Isibonelo Colliery in Mpumalanga Province of South Africa. In opencast mines, geological mapping has evolved over time and there have been challenges in extracting valuable information from exposed highwalls due to restricted access for safety reasons. A UAS was used at Isibonelo Colliery to conduct highwall mapping, using drone-based digital photogrammetry techniques. A demonstration survey was undertaken during February 2018. The highwall flyover demonstration was planned for two areas (North and South pits) where field control points were placed by the mine survey department. A contractor used a DJI Phantom 4 (Pro) for the highwall mapping. Raw data was processed within 48 hours and a 3D model of the mapped pit area was produced. Further data extraction included obtaining updated weathering and lithological contact elevations and thicknesses for use in short-term planning. The results showed a good correlation between the resource model and the UAS data model. The project was considered a success and highwall flyover mapping and is now standard practice at Isibonelo colliery.

Keywords

geological model, highwall mapping, coal mining, unmanned aircraft systems, UAS, drone, photogrammetry.

\section{Introduction}

Detailed geological mapping is crucial to the understanding of the structure of any mineral deposit. Several mapping methods may be applied depending on the available exposure/outcrop and nature of the orebody; for example, coal deposits typically suboutcrop only, therefore an opencut highwall provides the best exposure for mapping the geology. Mapped information, when incorporated into a resource model (generated from exploration borehole data), improves the understanding of the orebody or coal seam. This research paper focused on the use of unmanned aircraft system (UAS) technology for pit highwall mapping to generate data for updating geological models and avail the latest information to mine planning to improve the short-term plans.

The Isibonelo Colliery's geological model is updated annually and is termed a resource geological model, from which the mining model is built. This research was motivated by

the absence of a short-term geological model that could be used for short-term mine planning. Short-term models are built by mine geologists, when they take the latest release of the resource geological model and add in data as it becomes available from progressive mining. The data includes surveyed highwall seam-roof and/or seam-floor contacts, faults, dykes, blast-hole data, grade control hole data, and any other measurements deemed necessary for modelling. Highwall mapping with a survey total station is standard practice at Isibonelo Colliery. Recent technological advances have made new digital photogrammetry techniques available for mapping, with a camera being carried by a UAS which does highwall mapping. The process of short-term geological modelling allows for the incorporation of small-scale features, such as seam rolls and previously unidentified faults, which may not be obvious from broadly spaced exploration drill-hole data.

\section{The UAS technology and photogrammetric processing}

UAS technology has developed rapidly in South Africa in the last 6 years, following the regularization of its use by the country's controlling body, the South African Civil Aviation Authority (SACAA). These aircraft are also referred to as unmanned aerial vehicles (UAVs) or remotely piloted aircraft (RPAs). (Bucalo et al., 2015). The latest data from Business Insider indicates that there are 686 operators with remote pilot licences (RPLs) in South Africa. (Caboz, 2018).

1 Geology Manager-Production, Isibonelo Colliery, Anglo American Coal, South Africa.

2 School of Mining Engineering, University of the Witwatersrand, South Africa.

(c) The Southern African Institute of Mining and Metallurgy, 2019. ISSN 2225-6253. Paper received Oct. 2018; revised paper received Feb. 2019. 


\section{The use of unmanned aircraft system technology for highwall mapping at Isibonelo Colliery}

UASs are used for geological and topographic mapping, coastal control, landslide inspections, and are capable of integrating geophysical instrumentation like magnetic, electromagnetic, infrared, radar, and natural gamma ray sensors (Bucalo et al., 2015). Therefore, UASs have become a very important tool in the field of geoscience. The UAS discussed here uses a high-resolution camera that provides excellent ground coverage. The aircraft are generally inexpensive, with small commercial systems like the DJI Phantom 4 costing a few thousand rands. UASs are good at focusing on specific areas and do not require excessive flight lines to cover an area of interest.

UASs are a useful tool for extracting geological information from inaccessible areas. Data is generated rapidly; an area that takes three days of physical mapping may take only an hour or less to capture with a UAS. On completion of the UAS survey, the captured data is processed to produce a 3D surface model. In an open pit setting. The lithological contacts can then be mapped from the 3D model. Figure 1 shows one of the most modern UAS platforms used in South Africa, the DJI Phantom 4.

The DJI Phantom 4 has a camera with the capability of recording in RAW image format, which makes editing even easier. (Caboz, 2018). It is fitted with a 1-inch 20-megapixel sensor capable of shooting 4K/60fps video. Previously, the perspective gained from the UAS could only be attained from a manned aircraft, such as a helicopter. With the UAS it is possible to obtain digital images of the highwall as well as a multitude of digital terrain points, all in 3D space.

'Structure from Motion or SfM is a photogrammetric method for creating three-dimensional models of a feature or topography from overlapping two-dimensional photographs taken from many locations and orientations to reconstruct the photographed scene.' (Ullman, 1979). Thus, the software processes digital photographs, forming a 3D surface image or point cloud that can be compared against the 3D geological model.

Software packages like Agisoft, 3-D Rippler, and Geo Arc use algorithms (mathematical descriptors of each feature on the images) to create a 3D image through triangulation of matched image pairs. The result of the triangulation process is initially a sparse point cloud. Finally, a dense point cloud was produced for the highwall map. The greater the amount of collected high-resolution images, the more detailed the model produced, a dense 3D image of the pit.

The generated drone data model was validated against the resource model and actual survey data. CloudCompare, a 3D point cloud manipulation software package, was used to extract geological mapping data from the drone data model, which was then exported to Stratmodel (the geological modelling software used at Isibonelo) for update of the shortterm geological model.

\section{The Isibonelo UAS highwall mapping experience}

Isibonelo Colliery is situated near the northern margin of the Highveld Coalfield of Mpumalanga Province (Figure 2). The area is underlain by sedimentary strata of the Karoo Supergroup, which was deposited in the Permian period (248-290 Ma) (Anhaeusser and Maske, 1986). The Karoo sequence is made up predominately of sediments and is capped by a sequence of volcanic strata. Three stratigraphic units define the sedimentary succession of the Karoo Supergroup. From oldest to youngest, these are the Dwyka, Ecca, and Beaufort groups (Cadle, 1995). Coal seams of the

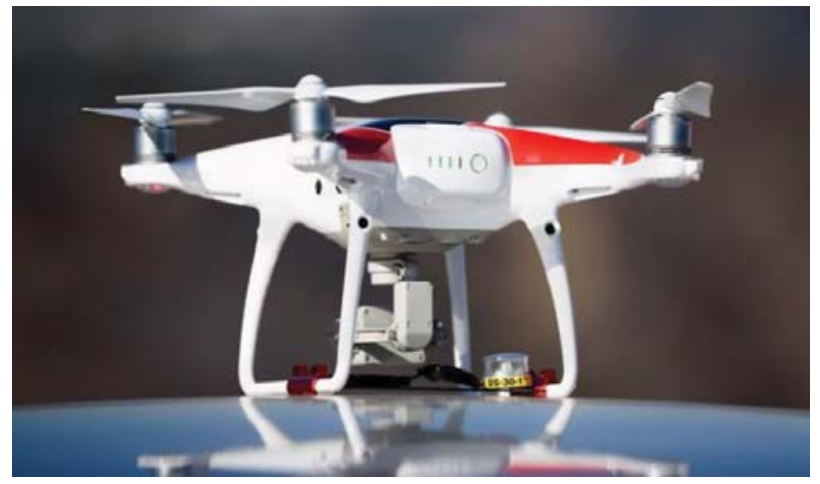

Figure 1-DJI Phantom 4 Pro UAS (Caboz, 2018)

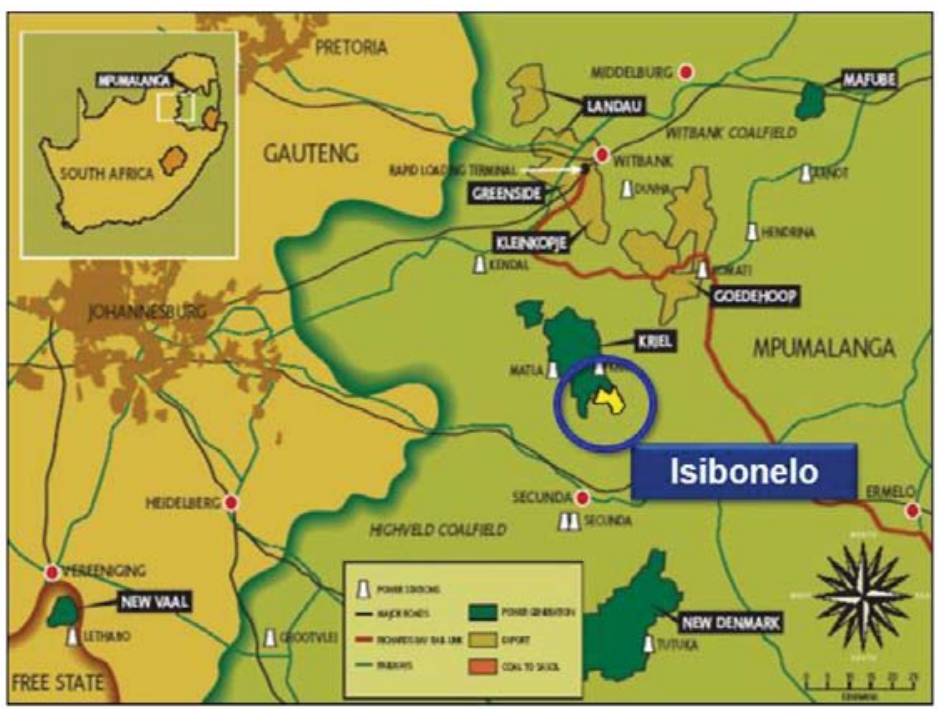

Figure 2-Location map of Isibonelo Colliery (Katuruza and Levings, 2017) 


\section{The use of unmanned aircraft system technology for highwall mapping at Isibonelo Colliery}

Highveld Coalfield are hosted within the Vryheid Formation of the Middle Ecca Group (270 Ma). Sediments of the Vryheid Formation represent coal-capped upward-fining cycles of clastic sediments deposited in a fluviodeltaic/shallow marine environment.

After considering several options for highwall mapping (e.g. total station survey) at Isibonelo, so that geological data could be produced for the short-term geological modelling, a UAS flyover was eventually given a trial in February 2018. The demonstration was carried out by Vidblast (Pvt) Ltd and Premier Mapping.

Permissions and flight planning were needed before the survey could be undertaken. The planning included delineation of the mapping area and determining the position of the surveyed marker pegs, which serve as ground control points (GCPs) for the survey. The coordinates (in .csv format) of the control pegs were sent to the service provider for flight planning purposes.

The demonstration was planned to cover selected areas in both the North and South pits. Figure 3 is an overview reference map of the survey areas.

Highwall mapping focused on delineation of the weathering horizons, namely the base horizon of 'softs', which include soils and sands (BHSO), the base horizon of friable weathering (BHFW), the base horizon of weathering (BHWE), and finally the interburden and the coal seams (no. 5 and no. 4 seams).

Figure 4 illustrates typical weathered horizons of a highwall where the UAS flyover mapping project was conducted at Isibonelo Colliery.

The South pit survey covered the furthest southern area between the S5 and S6 ramps, through to the end of the cut. For the North pit, the survey was between the N1 and N2 ramps (strip 31 and strip 32). Figure 5 illustrates the UAS flyover focus area in the North pit, as planned in the survey office in conjunction with the author

The UAS demonstration flight was planned for both pits on the same day. The area delineated in yellow in Figure 5 was defined by control points pegged on the ground by the surveyor prior to the flight.

Since this was the maiden flight, the process required a surveyor on site on the day of the flight to provide additional

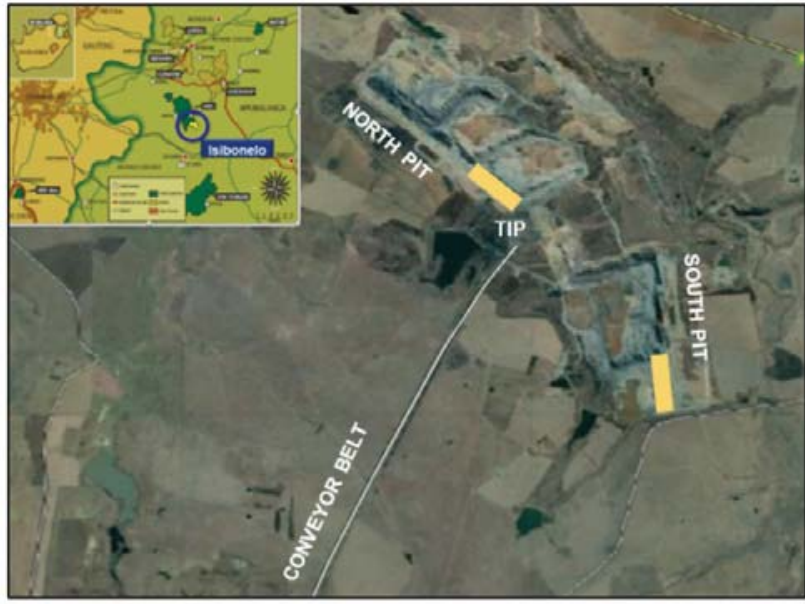

Figure 3-Isibonelo Colliery survey demonstration areas (yellow rectangles)

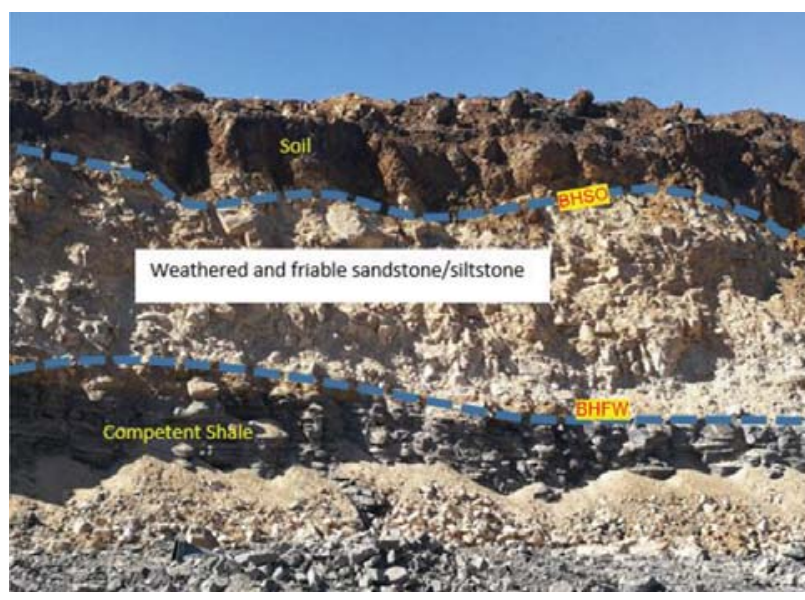

Figure 4-Typical highwall 'softs' mapping at Isibonelo Colliery (Katuruza, 2017)

control points if required. Additional control points were pegged on the day of the flight to ensure optimal georeferencing of the final 3D model.

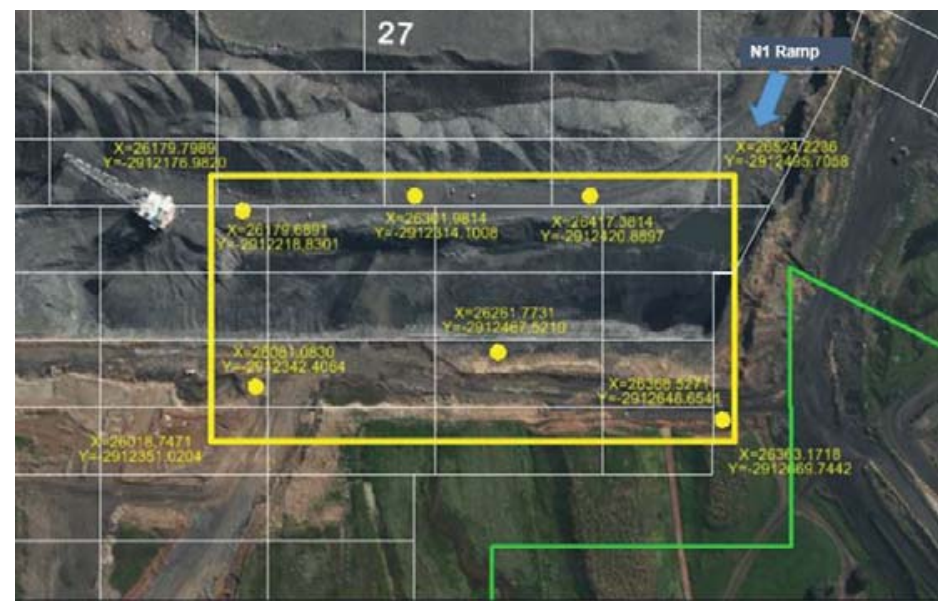

Figure 5-UAS flyover North pit (Survey Department, Isibonelo Colliery) 


\section{The use of unmanned aircraft system technology for highwall mapping at Isibonelo Colliery}

The demonstration flight was conducted by a licenced UAS pilot using the DJI Phantom 4. The UAS was flown from a mini-pad at the back of a utility vehicle parked on the dragline walkway bench on the low wall (spoils) side of the pit. The flight height was $50 \mathrm{~m}$ above the pit, with six flight lines being flown, each $500 \mathrm{~m}$ in length with a spacing of $60 \mathrm{~m}$ between lines.

\section{UAS data processing}

The data produced during the highwall mapping consisted of 3D point clouds comprising 13 million data-points over the South pit and 11 million data-points over the North pit. These were produced from digital photographs with a $60 \%$ overlap between images in the series. The UAS captured finer structures along the highwall with its high-resolution camera. The data was processed using Agisoft, a 3D photogrammetry software package for drone data processing. Agisoft builds a 3D point cloud using SfM. The data points were first cleaned out to remove any anomalies, especially the machinery that was working in the pit during the flyover, as this can distort the model. The GCPs assisted in georeferencing of the model within the surveyed area. The control points pegged on the ground are visible in the image of the model (Figure 6).

The software also processed the digital photos to form a 3D surface image, or textured mesh.

CloudCompare was used to compare the data provided by this survey to 3D data from the resource model. The UAS model was further validated by a surveyor and geologist who mapped the no. 4 and no. 5 seam top and bottom contacts in selected places, using a total station. The total station observations are shown on the 3D mesh model in Figure 7.

\section{Analysis of results}

Figure 8 illustrates a comparison of the bottom and top contacts of the sandstone (as derived from drone data) to the BHFW from the resource model. The sandstone contacts are currently not modelled in the resource model (using the defined weathering surfaces only from borehole data). This is the reason for the short-term model intervention.

The no. 4 seam top contact from the UAS data was compared to the geological model at the same point in space and is shown in Figure 9. There is a good correlation between the model contact and the results from the UAS data.

The highwall UAS mapping technique is quick in generating geological data for updating geological models (short-term modelling) compared to the total station highwall mapping technique, which is time-consuming and prone to human error.

The data resolution is exceptionally high, with a point cloud density of 13 million over an area of $120000 \mathrm{~m}^{2}$ for the South pit demo area.

\section{Conclusions and recommendations}

The spatial accuracy of the UAS data is high and eliminates human error when mapping the lithological contacts. The geological contacts are well defined in the 3D point cloud data, with the contacts already in a 3D coordinate system compatible with the geological model at Isibonelo Colliery.

A UAS flyover generates data within minutes (e.g. 35 minutes over an area $500 \mathrm{~m} \times 240 \mathrm{~m}$ ) over a very large area of the open pit. Furthermore, the digital photographs provide a usefull reference tool during the 3D modelling process. The turnaround time, from survey to completion of data processing, including a 3D model of the flown highwall area, can be as little as 48 hours, which is needed for decisionmaking in mining.

There is also the scope for zooming into specific problem areas and extracting additional information without

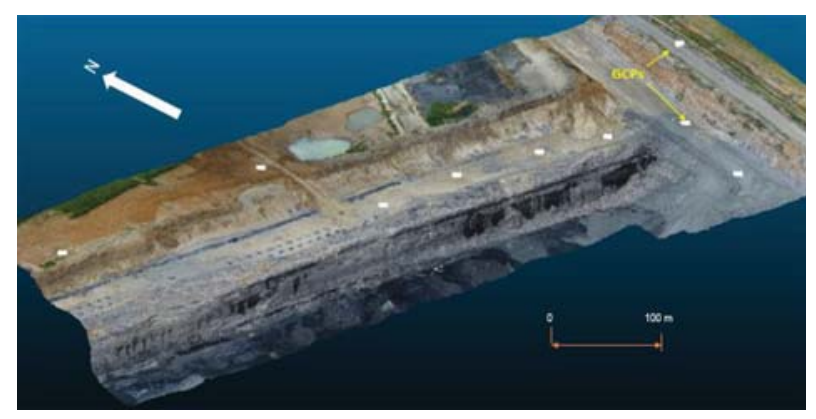

Figure 6-Far South pit, UAS 3D mesh model (de Bruyn, 2018)

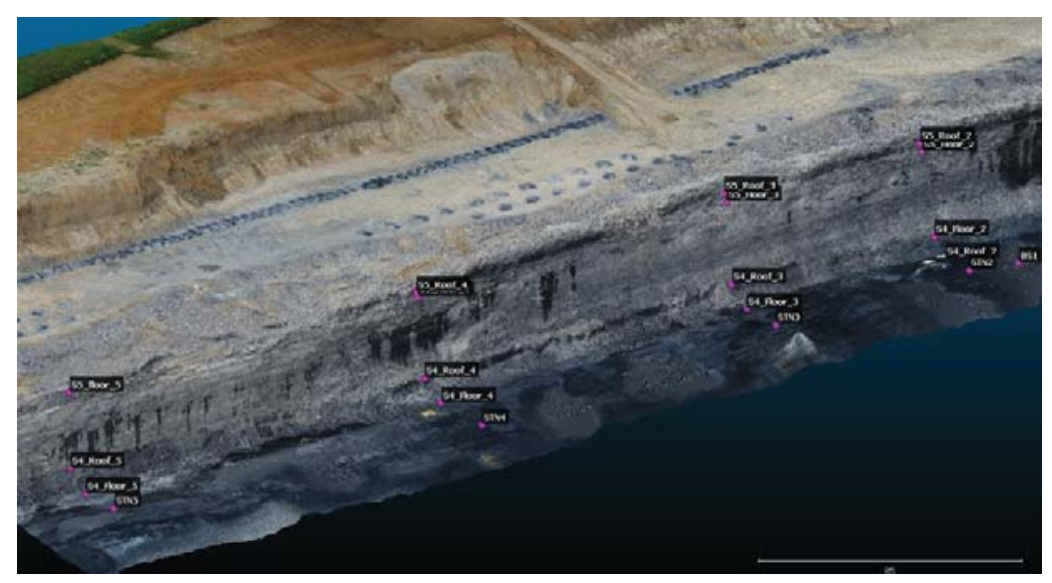

Figure 7-Far South pit mapped no. 4 seam and no. 5 seam contacts with total station points marked (Katuruza and Pretorius, 2018) 


\section{The use of unmanned aircraft system technology for highwall mapping at Isibonelo Colliery}

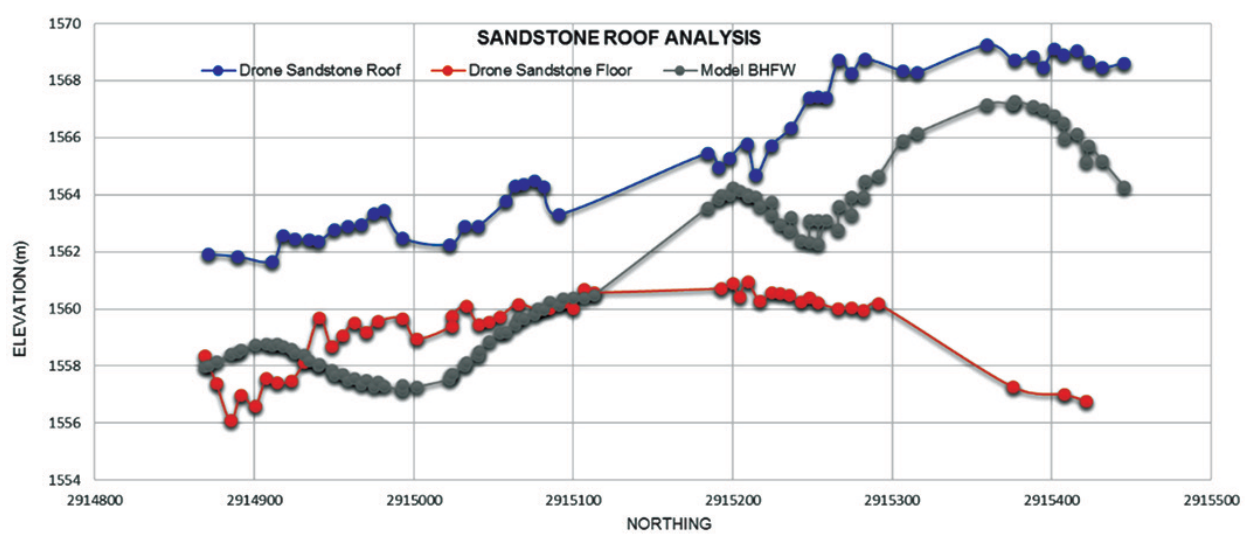

Figure 8-Far South pit sandstone resource compared with UAS data model (Pretorius, 2018)

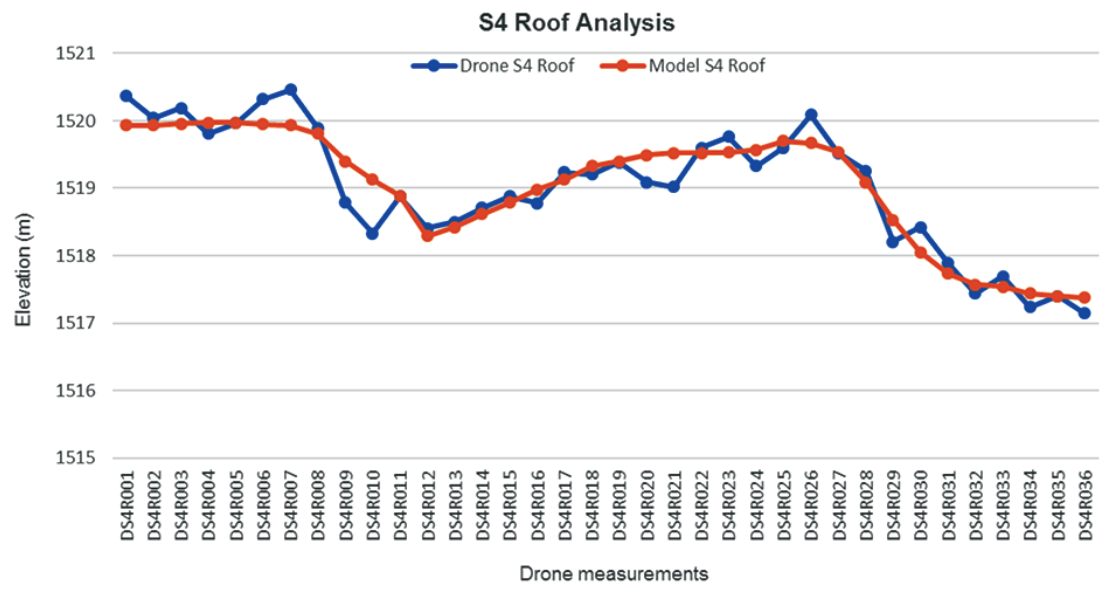

Figure 9-Strip18 no. 4 seam roof UAS compared with resource model (Katuruza, 2018)

compromising the safety of man and machinery. This is not possible with conventional highwall mapping, which is limited by access. The UAS highwall mapping technique proved it can generate large volumes of useful geological data over a short period of time, something not achievable through physical mapping.

The availability of new UAS technologies coupled with photogrammetry software to process data has improved the speed and accuracy of geological data acquisition and interpretation at Isibonelo Colliery.

Geologists should be equipped with this new technology to update short-term geological models timeously. Training on software for building 3D models and extrapolation of data is also recommended for geologists using UAS for highwall mapping.

In addition to highwall mapping, UAS technology is exceptionally useful in a mining environment, having numerous other applications which include blast monitoring, stockpile reconciliations, in-pit coal reconciliation, and inspection of mine infrastructure.

\section{References}

AnHaeusser, C.R. and Maske, S. 1986. Mineral Deposits of South Africa (Vols. 1-2). Geological Society of South Africa, Johannesburg. BIRCH, J. 2004. 3DM Analyst 2.1 trial at BMA Coal's Goonyella Mine. ADAM
Technology. http:// www.adamtech.com.au/3dm/goonyella\% 20report\%20(abridged).pdf

Bucalo, F., D'Allesando, A., Colteli, M., and Martorana, R. 2015. Drones: new technologies for geophysics? Near Surface Geoscience 2015. Proceedings of the 21st European Meeting of Environmental and Engineering Geophysics, Turin, Italy. European Association of Geoscientists \& Engineers, The Netherlands. pp. 6-10.

CABOZ, J. 2018. Business Insider South Africa. https://www.businessinsider.co.za/sas-most-popular-drone-remains-wayahead-of-its-competitors-here-are-the-5-reasons-why-2018-3

CADLE, A.B. 1995. Depositional systems of the Permian Vryheid Formation, Highveld Coalfield, South Africa, Their relationship to coal seam occurence and distribution. PhD thesis, University of the Wistwatersrand, Johannesburg

DE Bruyn, D. 2018. Drone hole identification. Johannesburg. Unpublished report.

KaturuZa, M. 2017. Competent Person Report, Resources Isibonelo Colliery. Unpublished meport

Katuruza, M. 2017. Competent Person's Report for Isibonelo Colliery. Unpublished, mine internal document.

KATURUZA, M. and Levings, S. 2017. Isibonelo Colliery CPR presentation. Unpublished internal presentation.

Katuruza, M. and Pretorius, D. 2018. Improving short term modelling using drone data at Isibonelo Colliery. Unpublished internal document.

PREToRius, D.J. 2018. Isi drone data. Unpublished internal report.

Ullman, S. 1979. Structure from motion (SfM) photogrammetry. Proceedings the Royal Society B, vol. 203, no. 1153. The Royal Society, London: pp. 405-426. : https://royalsocietypublishing.org/doi/abs/10.1098/ rspb.1979.0006 